\title{
Combustion Characteristics of Butane Porous Burner for Thermoelectric Power Generation
}

\author{
K. F. Mustafa, ${ }^{1}$ S. Abdullah, ${ }^{1}$ M. Z. Abdullah, ${ }^{2}$ and K. Sopian' \\ ${ }^{1}$ Department of Mechanical and Materials Engineering, Faculty of Engineering and Built Environment, \\ Universiti Kebangsaan Malaysia (UKM), 43600 Bangi, Selangor, Malaysia \\ ${ }^{2}$ School of Mechanical Engineering, Universiti Sains Malaysia Engineering Campus, Seri Ampangan, \\ 14300 Nibong Tebal, Penang, Malaysia
}

Correspondence should be addressed to K. F. Mustafa; mekhairil@usm.my

Received 25 September 2014; Revised 11 March 2015; Accepted 24 March 2015

Academic Editor: Kalyan Annamalai

Copyright ( 2015 K. F. Mustafa et al. This is an open access article distributed under the Creative Commons Attribution License, which permits unrestricted use, distribution, and reproduction in any medium, provided the original work is properly cited.

\begin{abstract}
The present study explores the utilization of a porous burner for thermoelectric power generation. The porous burner was tested with butane gas using two sets of configurations: single layer porcelain and a stacked-up double layer alumina and porcelain. Six PbSnTe thermoelectric (TE) modules with a total area of $54 \mathrm{~cm}^{2}$ were attached to the wall of the burner. Fins were also added to the cold side of the TE modules. Fuel-air equivalence ratio was varied between the blowoff and flashback limit and the corresponding temperature, current-voltage, and emissions were recorded. The stacked-up double layer negatively affected the combustion efficiency at an equivalence ratio of 0.20 to 0.42 , but single layer porcelain shows diminishing trend in the equivalence ratio of 0.60 to 0.90 . The surface temperature of a stacked-up porous media is considerably higher than the single layer. Carbon monoxide emission is independent for both porous media configurations, but moderate reduction was recorded for single layer porcelain at lean fuel-air equivalence ratio. Nitrogen oxides is insensitive in the lean fuel-air equivalence ratio for both configurations, even though slight reduction was observed in the rich region for single layer porcelain. Power output was found to be highly dependent on the temperature gradient.
\end{abstract}

\section{Introduction}

The merits of utilizing thermoelectric (TE) devices in various energy conversion systems have led to their application in many engineering fields. Coupled with strong drives for research and developments, numerous scientists have shown appreciable interest in these devices owing to their unique and easy method of transforming thermal energy into electricity. The working principle of TE devices is practically simple, relying primarily on the temperature difference between the hot and cold sides of the TE modules for electricity power generation. The generated temperature difference agitated the electron charge carrier and thereby resulted in the flow of electric current in the circuit. Of practical significance is that the modules are generally quiet and highly reliable, and their compactness allows easy integration into a burner or furnace.

Thermal to electric energy transformation that pertains to thermoelectric system takes place when the heat produced from the combustion products in the burner flows through the TE modules. The temperature gradient between the hot combustion gases and relatively cold ambient triggers the electricity flow through the module and into the circuit. In general, the burners for TE applications can be fired using many types of hydrocarbon fuels, either liquid or gaseous. Qiu and Hayden [1], for instance, studied the thermoelectric power generation using natural gas-fired burner. The electricity generated was used to power the electrical components for residential heating system. Their work was further extended to investigate the beneficial effect of including an air recuperator and additional TE modules in the system, Qiu and Hayden [2]. The apparent advantage of an air recuperator was evident with an improved electrical efficiency reported in their later work. A number of useful applications of TE modules have also been disseminated by other notable investigators, for example, in a cook stove by Champier et al. [3], and exhaust gas extraction for vehicular applications, as 
shown by Yang and Stabler [4], Kim et al. [5], and Deng et al. [6]. With regards to butane gas, despite its popularity as household portable burner, considerable researches on it remained largely shallow. Posthill et al. [7] endeavored on the application of butane gas for TE generator by demonstrating a mini combustor as a heat source for silicon germanium (SiGe) TE modules. Much earlier, Rahman and Shuttleworth [8] devised an experiment of TE applications using butane gas for powering laptop computer. Other than these, Yoshida et al. [9] attempted a catalytic microcombustor fired by butane and hydrogen gas in TE power generation. Although the abovementioned studies did much to elucidate the TE power generation covering wide spectrum of applications, combustion and emission aspects of the burner itself are generally neglected. Lack of understanding and inadequate information from the works cited previously highlighted the unintended voids left by these authors in omitting the burner performance and gas emission from the burner. This however opens up new avenues for researchers to realize that much effort is still needed to cover these aspects to regard TE modules as a good candidate for TE power generation. The present work is therefore initiated to expound more succinctly the overall performance of the TE power generation system, by including the thermal characteristics of the burner.

Porous media combustion is one of the newer techniques invented to achieve combustion stability with concomitant reduction in emissions. The essential feature of porous media combustion fundamentally pertains to heterogeneous combustion between the solid matrix with its void filled with fluids. Howell et al. [10] expounded that the combustion of fuel and air mixture in the porous matrix is rigorously heated via enhanced convective mode as the reactants flow through the interstitial voids in the matrix. An enhanced heat transfer mechanism between the combustion products and porous structure is beneficial in allowing greater control of flame stability with improved radiant energy. With better flame stability, fuel-air equivalence ratio can be widened and thereby the burner can be operated at leaner equivalence ratio. This will then be potentially translated into an improved overall efficiency and hazardous exhaust gases associated with emission products can be ameliorated.

Considerable research effort has also been expended in devising stacked-up porous media to obtain flame stability for both liquid and gaseous fuels. Kerosene fuel combustion using silicone-carbide-coated carbon-carbon (C-C) foam was comprehensively tested by Periasamy et al. [11], Vijaykant and Agrawal [12], and Periasamy and Gollahalli [13]. Jugjai and Polmart [14] made use of alumina spheres for kerosene fuel evaporation enhancement in two-section porous burner. Combustion of natural gas in silicon carbide coated C-C porous material was elucidated by Marbach and Agrawal [15]. Smucker and Ellzey [16] elicited the merits of yttria stabilized zirconia in stretching the operating range of fuel-air equivalence ratio of propane and methane in a two-section porous burner. The findings exposited by these researchers generally agree with the apparent advantages of incorporating the stacked-up porous media in a burner. However, coupling the inherent advantages of a porous burner for TE power generation requires comprehensive temperature and burner efficiency and these remain largely unexplored. The published work of Hanamura et al. [17] was primarily restricted towards numerical aspects of superadiabatic combustion in investigating the use of porous element for TE power generation. Indepth understanding and sufficient knowledge have not been generated since, and this forms the thrust and motivation for designing the present work.

The primary focus of the study undertaken was to evaluate the electricity generation using thermoelectric modules (TEM) from the combustion of butane gas in a porous burner. The study covers two types of porous media configurations, using single layer porcelain and double layer alumina and porcelain. The aim was further narrowed to assess the thermoelectric power generation at several ranges of operating fuel-air equivalence ratio. Combustion characteristics are discussed in terms of the temperature profiles, combustion efficiency, and the emissions generated as the products of combustion. Results yielded in the study are analyzed for both sets of experiments and presented to demonstrate the feasibility of utilizing stacked-up porous media for TE power generation system.

\section{Materials and Methods}

2.1. Experimental Setup and Procedure. The design concept in this work is to integrate a porous burner operating on butane gas with TE modules for the generation of electricity. TE modules allow temperature difference between two dissimilar conductors to produce voltage via Seebeck effect. The electricity power generation system consists essentially of a hexagonal burner and six PbSnTe TEM cells $(3 \mathrm{~cm} \times 3 \mathrm{~cm})$ attached to the side wall of the burner.

The stainless steel burner was fabricated in the common machine workshop in the School of Mechanical Engineering, Universiti Sains Malaysia (USM). Stainless steel with a thickness of $3 \mathrm{~mm}$ was chosen owing to the fact that it has lower thermal conductivity $(16.2 \mathrm{~W} / \mathrm{mK})$. Low thermal conductivity ensures high temperature encapsulation for the burner. The burner can be divided into two sections: (1) the main combustion chamber to house the porous media, and (2) a base premixed chamber. The main combustion chamber was designed to be hexagonal in shape with $4.5 \mathrm{~cm}$ width for all sides of the burner. The choice of the hexagonal shape was solely made for the flexible placement and easy positioning of the TEM cells even though no geometric optimization was carried out for the dimensions of the burner. The hexagonal shape burner was the primary combustion zone and filled with two types of porous media; the top layer is alumina $\left(\mathrm{Al}_{2} \mathrm{O}_{3}\right)$ and the bottom layer is porcelain. Alumina has a thickness of $12.7 \mathrm{~mm}$ with 8 pores per $\mathrm{cm}(8 \mathrm{ppcm})$ and $85 \%$ porosity. It was chosen owing to its high working temperature, thermal shock resistance, and low pressure drop. The bottom layer is porcelain with a thickness of $15.0 \mathrm{~mm}$ having $16 \mathrm{ppcm}$ and $86 \%$ porosity. Both porous media were carefully placed inside the chamber and cemented with special glue at all contacting edges of the burner. A tight fit between the porous media and burner is critical because unwanted gaps between the two could cause the flame to develop 
and propagate around the porous media. When the burner was operated with double layer porous media, alumina was carefully placed on top of porcelain so that there was no air space between the two.

The base premixed chamber is a small hexagonal chamber which was designed to increase the residence time of the fuel and air mixture prior to the entrance of the main combustion zone. This chamber was also fabricated using stainless steel and welded together to the bottom part of the primary combustion zone of the burner to create a single piece. The height of the chamber is $8 \mathrm{~cm}$. The bottom end of the chamber forms a fuel feeding side which was connected to the fuel supply pipe from the butane gas container. All TEM cells were positioned equispaced around the wall of the primary combustion zone and fixed in their position to the wall of the main combustion zone by a thermal pad. The thickness of the thermal pad is negligible compared to the overall dimensions of the combustion zone. This implies that the temperature fluctuation across the pad can be safely neglected without significant influence on the overall heat transfer across the TE modules. There are six TEM cells with a total area of $54 \mathrm{~cm}^{2}$. The thermoelectric elements in the module are made from PbSnTe doped in either $\mathrm{p}$ - or $\mathrm{n}$-type semiconductor properties. Since electricity generation using TEM cells is strongly influenced by the temperature gradient between the hot and cold surfaces, six steel fins were added to the ambient side TE modules to enhance cooling. The terminals of all TEM cells were electrically connected in series.

The working fuel used throughout the entire experiment is butane (chemical formula $\mathrm{C}_{4} \mathrm{H}_{10}$ ). The butane gas is kept in a container with a capacity of $230 \mathrm{~g}$ similar to the one used in a commercially available portable cooking burner. It was tightly secured in its place with a manual locking device and put in the horizontal plane housing. The fuel releasing knob can be set from the minimum (zero fuel flow rate) to the maximum (maximum fuel flow rate) and it was connected to the opening of the butane fuel supply. During the experiment, the fuel releasing knob was adjusted and only used to approximate the butane gas supplied, since the fuel flow rate was precisely metered using Vogtlin flow regulator GCRC9KA BA20 (Switzerland). The flow meter was calibrated in the range of $0-2.000$ liter per minute (lpm) with flow accuracy of up to $0.005 \mathrm{lpm}$. It was supplied through reinforced plastic fuel tubing with an internal diameter of $4 \mathrm{~mm}$. The pipe was connected to the entrance of the premixed chamber of the burner. It should be noted that the air admission into the premixed chamber was done in the artificial conditions of inducement via fuel entrainment. Since the fuel feeding pipe sits only few millimeters from the mouth belly of the premixed chamber, sufficiently high gas velocity of butane created the air inducement and entrained the air into the premixed chamber.

Throughout this study, experiments were conducted by varying the fuel flow rate to demonstrate the changing values of the fuel-air equivalence ratio $(\phi)$ on the electricity power generation. Two sets of experiments were conducted, with single layer porcelain porous medium and double layer alumina and porcelain porous media. In a double layer configuration, alumina was stacked on top of porcelain and

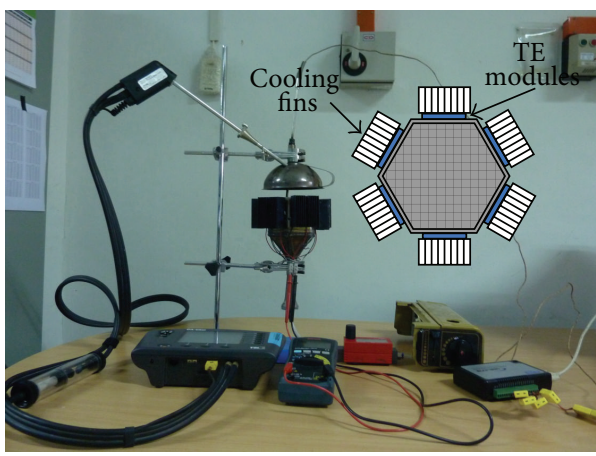

FIGURE 1: Experimental setup without the thermal imager.

cemented at the edges to eliminate any air gaps between the two porous media. The entire experiment was conducted by varying the fuel-air equivalence ratio from the leanest to the richest. The leanest equivalence ratio was not necessarily the theoretical value for butane, but it was rather observed based on the flame stability during combustion with porous media. The stable flame is defined as one that is entirely contained within or on the porous medium for a given fuel and air flow rate and remained steady (Periasamy and Gollahalli [13]). Even though combustion was successfully initiated for all intended values of fuel-air equivalence ratio, it could not be stabilized for periods longer than 15 minutes without the flame either flashing back at lower airflows and igniting the spray or blowing out the downstream end of the porous media at higher flow rates.

For each set, the emission level of carbon monoxide (CO) and nitrogen oxides $\left(\mathrm{NO}_{x}\right)$ was recorded using a portable combustion analyzer CA-CALC 6203 suitable for quasicontinuous measurement of combustion products. The data were later saved on a PC as a Microsoft Excel worksheet. The probe tip of the combustion analyzer was positioned $10 \mathrm{~cm}$ from the top surface of the porous media and fixed at the central position of the porous chamber. The surface temperature of the porous media was imaged using Fluke Ti27 $9 \mathrm{~Hz}$ thermal imager which provides accurate surface temperature distribution. The surface temperature was only captured after the emission gases were recorded by the combustion analyzer. Since both apparatuses were in identically positioned on top of the porous burner, the readings were done alternately. The temperatures of the fins attached to the thermoelectric modules were also captured using the thermal imager. The uncertainty in temperature measurement is $\pm 2^{\circ} \mathrm{C}$. The current-voltage readings were determined using Sanwa Digital Multimeter CD771 with series connection for all terminals. Figure 1 depicts the actual experimental setup without the thermal imager and Figure 2 represents the schematic diagram. The detail dimensions of the burner are shown in Figure 3.

2.2. Quality of the Experimental Data. Experiments for both sets of burner configurations were repeated thrice to ensure the repeatability and the reliability of the measured data. For all experimental data, the mean value $(\bar{X})$ and the standard deviation $\left(S_{X}\right)$ are expressed as follows $[18,19]$ : 


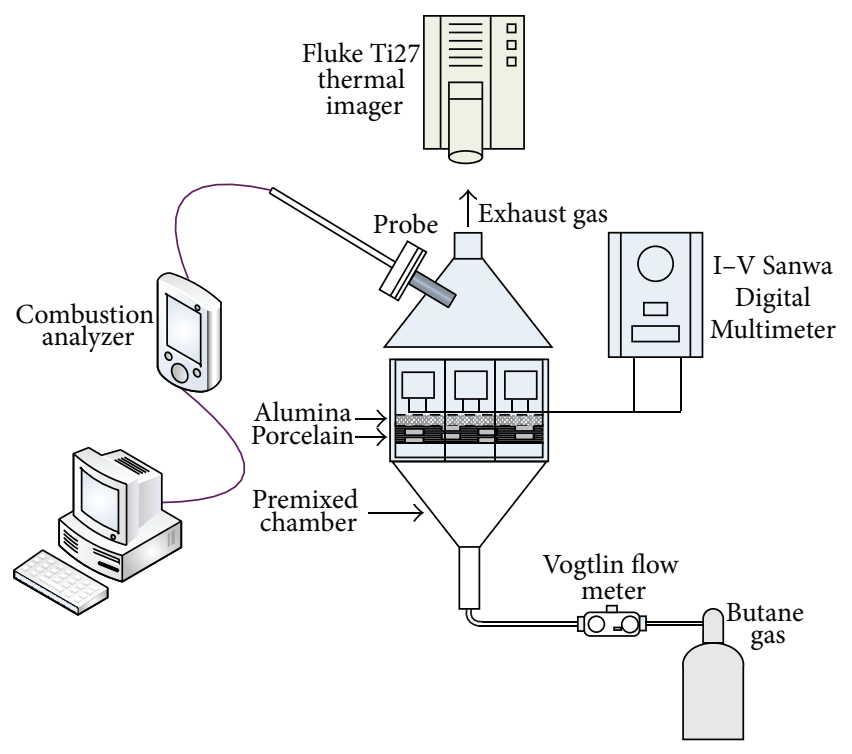

FIGURE 2: Schematic diagram including the thermal imager. The thermal imager was positioned on top and in the center of the porous burner.

$$
\begin{gathered}
\bar{X}=\frac{1}{n} \sum_{i=1}^{n} X_{i} \\
S_{X}=\left[\frac{1}{n-1} \sum_{i=1}^{n}\left(X_{i}-\bar{X}\right)^{2}\right]^{1 / 2}
\end{gathered}
$$

Uncertainty is defined as $[18,19]$

$$
\text { Uncertainty }=\frac{\text { Standard deviation }}{\text { Mean value }} \times 100 \% \text {. }
$$

The values of $\bar{X}, S_{X}$, and uncertainty for the measured parameters are tabulated in Tables 1 and 2 . The experimental data are tabulated for the surface temperature of the porous media, mass flow rate of butane $\left(m_{f}\right)$, voltage $(V)$, current $(I)$, carbon monoxide $(\mathrm{CO})$, and nitrogen oxides $\left(\mathrm{NO}_{x}\right)$.

The measured experimental data are reliable since the maximum uncertainty was only $2.8 \%$, which can be regarded as very low. The uncertainty of the measured data is shown throughout the range of fuel-air equivalence ratio for single and layer and double layer are shown in Tables 3 and 4, respectively.

The maximum uncertainty for single layer porcelain and double layer porcelain and alumina is $2.8 \%$ and $2.2 \%$, respectively.

2.3. Numerical Investigation. The numerical procedure adopted in this study is used to determine the influence of porous material properties on the thermal characteristics of the burner. The governing equations for mass, solid energy, gas energy, and gas species are used [16]:

$$
\begin{gathered}
\frac{\partial\left(\rho_{g} \varepsilon\right)}{\partial t}+\frac{\partial\left(\rho_{g} \varepsilon u\right)}{\partial x}=0 \\
\rho_{g} C_{g} \varepsilon \frac{\partial T_{g}}{\partial t}+\rho_{g} C_{g} \varepsilon u+\Sigma \rho \varepsilon Y_{i} V_{i} C_{g i} \frac{\partial T_{g}}{\partial x}+\varepsilon \Sigma \dot{\omega}_{i} h_{i} W_{i} \\
=\varepsilon \frac{\partial}{\partial x}\left(\left(k_{g}+\rho C_{p} D_{I I}^{d}\right) \frac{\partial T_{g}}{\partial x}\right)-h_{v}\left(T_{g}-T_{s}\right), \\
\rho_{s} C_{s} \frac{\partial T_{s}}{\partial t}=k_{s} \frac{\partial^{2} T_{s}}{\partial x^{2}}+h_{v}\left(T_{g}-T_{s}\right)-\frac{\partial q_{r}}{\partial x}, \\
\rho_{g} \varepsilon \frac{\partial Y_{i}}{\partial t}+\rho_{g} \varepsilon u \frac{\partial Y_{i}}{\partial x}+\frac{\partial}{\partial x}\left(\rho \varepsilon Y_{i} V_{i}\right)-\varepsilon \dot{\omega}_{i} W_{i}=0,
\end{gathered}
$$

where $\varepsilon$ is porosity, $\rho$ is gas density, $u$ is gas velocity, $t$ is time, $C_{g}$ is the specific heat of gas, $T_{g}$ is temperature of the gas, $x$ is the distance, $Y_{i}, V_{i}, C_{g i}, \omega_{i}, h_{i}$, and $W_{i}$ are the mass fraction, diffusion velocity, specific heat, molar rate of production, molar enthalpy, and molecular weight of the $i$ th species, respectively, $k_{g}$ is gas thermal conductivity, $h_{v}$ is the volumetric heat transfer coefficient between the porous media and the gas, $T_{s}, C_{s}$, and $k_{s}$ are the temperature, specific heat, and effective thermal conductivity of the porous medium, respectively, and $q_{r}$ is radiant heat flux in the $x$ direction [16].

\section{Results and Discussion}

3.1. Surface and Submerged Temperature Distributions. The computed surface and submerged temperature distributions against porous material thickness at various fuel-air equivalence ratios are shown in Figure 4. In all cases, the submerged temperature distributions increase as the thickness of the porous material increases. In the transition zone of the burner $(x=15.0 \mathrm{~mm})$, noticeable increase in the submerged temperature was observed. This has the effect on stabilizing the combustion zone in the porous burner. A change in the pore size has significantly affected the downstream temperature distributions, as the computed temperature gradually increases until the top layer of the double layer porcelain and alumina. The predicted and the experimental values are tabulated in the inset of Figure 4 . It can be seen that the predicted and experimental values of the surface temperatures agree well within $5 \%$ range. The sensitivity of the combustion zone in the submerged layer of the porous alumina towards the flow velocity is thought to be the contributing factor in the experimental values. It can also be seen in Figure 4 that the influence of fuel-air equivalence ratio on the submerged temperature profiles is only marginal, since no obvious pattern can be interpreted from the figure. Unlike the free flame combustion, combustion in porous media is relatively complex, and enriching the fuel-air equivalence ratio is not normally accompanied by an increase in the submerged temperature distributions.

3.2. Combustion Efficiency. Fuel-air equivalence ratio is defined as the ratio between the actual fuel-air mixture and the stoichiometric fuel-air mixture. For butane $\left(\mathrm{C}_{4} \mathrm{H}_{10}\right)$, using the stoichiometric combustion equation, it can be 


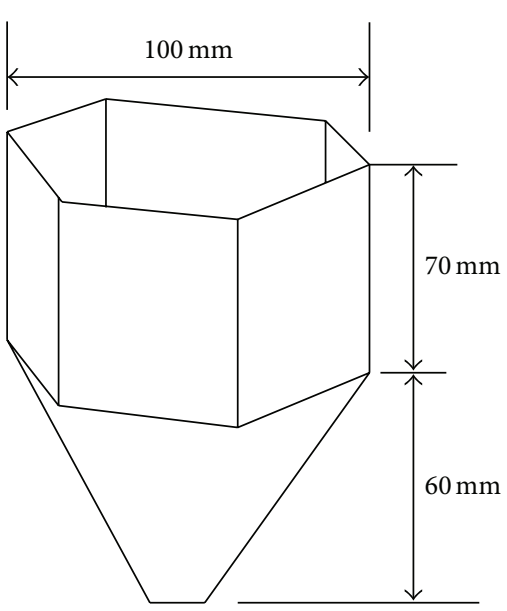

(a)

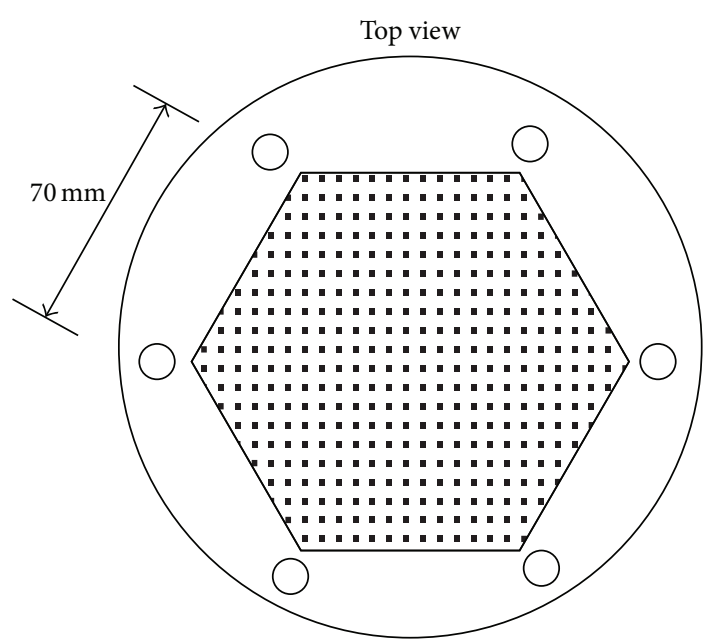

(b)

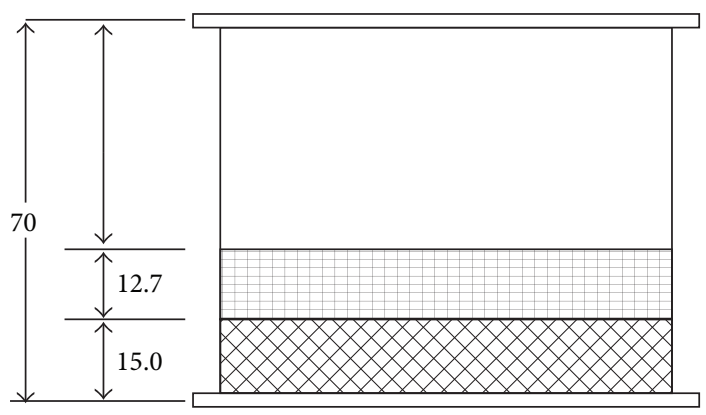

Alumina

Porcelain

(c)

FIGURE 3: Burner drawing and dimensions: (a) isometric view, (b) top view, and (c) side view without the premixing chamber. All dimensions are in $\mathrm{mm}$ and figures are not drawn to scale.

TABLE 1: $\bar{X}, S_{X}$, and uncertainty for single layer porcelain.

\begin{tabular}{lccccc}
\hline Measured parameters & $\begin{array}{c}\text { Surface temperature } \\
\left({ }^{\circ} \mathrm{C}\right)\end{array}$ & $\begin{array}{c}\dot{m}_{f} \\
\mathrm{~L} / \mathrm{min}\end{array}$ & $\begin{array}{c}V \\
\text { Volt }\end{array}$ & $\begin{array}{c}I \\
\mathrm{Amp}\end{array}$ & $\begin{array}{c}\mathrm{CO} \\
\mathrm{Nom}\end{array}$ \\
\hline Mean value, $\bar{X}$ & 384.3 & 1.105 & 9.96 & 0.077 & 828 \\
Standard deviation, $S_{X}$ & 2.9 & 0.020 & 0.12 & 0.00216 & 24 \\
Uncertainty & $0.7 \%$ & $1.8 \%$ & $1.2 \%$ & $2.8 \%$ & 0 \\
\hline
\end{tabular}

derived from chemical composition that the stoichiometric fuel-air mixture is 0.065 . In our study, the fuel-air equivalence ratio, $\phi$ was varied by adjusting the amount of butane gas supplied into the burner. Experiments were conducted for both single layer (using porcelain only) and double layer alumina and porcelain. For a meaningful comparison, the fuel-air equivalence ratio was intended to be identical for both configurations of porous media, but it was evidently observed during the experiment that combustion instability has demarcation effect on the range of fuel-air equivalence ratio covered in the experiment. For single layer porcelain, the "rich" fuel-air equivalence ratio was extended until the combustion reached the critical flashback region, where the associated flashback triggered the onset of flame shifting towards the premixed chamber and extinguished. This flashback point for single layer porcelain was found to be approximately at fuel-air equivalence ratio of 0.90 . For double layer alumina and porcelain, the maximum fuel-air equivalence ratio was marginally lower compared to single layer porcelain and the value of 0.62 was recorded in this experiment. The sensitivity of the flame stabilization towards fuel-air equivalence ratio was also apparent in the lean region with the minimum values of 0.34 and 0.20 for single and double layer porous media, respectively. In the rich region of equivalence ratio, flashback is the primary issue, but the lean region is moderately dominated to some extent by 
TABLE 2: $\bar{X}, S_{X}$, and uncertainty for double layer porcelain and alumina.

\begin{tabular}{lccccc}
\hline Measured parameters & $\begin{array}{c}\text { Surface temperature } \\
\left({ }^{\circ} \mathrm{C}\right)\end{array}$ & $\begin{array}{c}\dot{m}_{f} \\
\mathrm{~L} / \mathrm{min}\end{array}$ & $\begin{array}{c}V \\
\text { Volt }\end{array}$ & $\begin{array}{c}I \\
\mathrm{Amp}\end{array}$ & $\begin{array}{c}\mathrm{CO}_{x} \\
\mathrm{ppm}\end{array}$ \\
\hline Mean value, $\bar{X}$ & 576.7 & 0.880 & 11.03 & 0.083 & 643 \\
Standard deviation, $S_{X}$ & 5.2 & 0.015 & 0.20 & 0.001 & 32 \\
Uncertainty & $0.9 \%$ & $1.7 \%$ & $1.8 \%$ & $1.1 \%$ & 0 \\
\hline
\end{tabular}

TABLE 3: Uncertainty of the measured data for single layer porcelain in the range of fuel-air equivalence ratio.

\begin{tabular}{|c|c|c|c|c|c|c|}
\hline \multirow{3}{*}{ Fuel-air equivalence ratio } & \multicolumn{6}{|c|}{ Uncertainty } \\
\hline & Surface temperature & $\dot{m}_{f}$ & $V$ & $I$ & $\mathrm{CO}$ & $\mathrm{NO}_{x}$ \\
\hline & $\left({ }^{\circ} \mathrm{C}\right)$ & $\mathrm{L} / \mathrm{min}$ & Volt & Amp & ppm & ppm \\
\hline 0.38 & $0.8 \%$ & $2.1 \%$ & $1.1 \%$ & $2.2 \%$ & $1.1 \%$ & $1.0 \%$ \\
\hline 0.39 & $1.0 \%$ & $2.2 \%$ & $1.4 \%$ & $2.8 \%$ & $1.1 \%$ & $1.0 \%$ \\
\hline 0.41 & $0.9 \%$ & $1.8 \%$ & $1.2 \%$ & $2.3 \%$ & $1.6 \%$ & $1.0 \%$ \\
\hline 0.50 & $0.6 \%$ & $1.5 \%$ & $1.1 \%$ & $2.1 \%$ & $1.2 \%$ & $0.0 \%$ \\
\hline 0.51 & $0.6 \%$ & $1.2 \%$ & $1.2 \%$ & $0.8 \%$ & $1.1 \%$ & $0.0 \%$ \\
\hline 0.58 & $0.7 \%$ & $0.9 \%$ & $1.5 \%$ & $1.6 \%$ & $1.6 \%$ & $0.0 \%$ \\
\hline 0.60 & $0.8 \%$ & $2.4 \%$ & $0.9 \%$ & $1.7 \%$ & $1.2 \%$ & $0.0 \%$ \\
\hline 0.62 & $1.1 \%$ & $2.3 \%$ & $1.0 \%$ & $1.8 \%$ & $1.1 \%$ & $1.0 \%$ \\
\hline 0.65 & $1.2 \%$ & $2.6 \%$ & $1.0 \%$ & $2.5 \%$ & $1.4 \%$ & $2.0 \%$ \\
\hline 0.67 & $1.5 \%$ & $2.1 \%$ & $0.9 \%$ & $2.8 \%$ & $1.3 \%$ & $0.0 \%$ \\
\hline 0.95 & $1 . \%$ & $1.2 \%$ & $0.8 \%$ & $2.6 \%$ & $1.3 \%$ & $0.0 \%$ \\
\hline
\end{tabular}

blowoff phenomenon. Blowoff occurs at low fuel flow rate and the diminishing fuel-air equivalence ratio exacerbated the flame stability. Even though the reduced stability of the flame was quite subtle, it was visually evident when the flame began to extinguish at the top surface of the porous media during the experiment. The beneficial effect of stacking up the porous media with different pore size can be noticed at leaner equivalence ratio. The lean limit with double layer porous media suggests that a slight improvement in the flame stability with concomitant reduction in the equivalence ratio occurs in the burner. This was confirmed by an earlier work of Hsu et al. [20] in their experiment using stacked porous ceramic burner with premixed methane gas. Without making quantitative comparison due to the difference in a fuel, the observed flame stability at lean limit of equivalence ratio in this study was remarkably similar to the reported work of Hsu et al. [20]. The transition from large (alumina) to small (porcelain) pore size porous media also seems to enhance the flame stability by reducing the flame speed and combustion intensity. To illustrate the effectiveness of the thermal energy conversion in our study, the combustion efficiency is plotted against fuel-air equivalence ratio and shown in Figure 5. The combustion efficiency is calculated using the following expression [21]:

$$
=1-\frac{\dot{m}_{\text {net }} X_{k} H_{\text {coal }}+\dot{n} y_{\mathrm{CO}} H_{\mathrm{CO}}+\dot{n} \bar{c}_{p}\left(T-T_{o}\right)+U A\left(T-T_{o}\right)}{\dot{m}_{f} Q_{\text {net }}},
$$

where $\dot{m}_{\text {net }}$ is the mass flow rate discharge from the combustor and $X_{k}$ is the carbon content in the discharged solid particles. The first term on the right-hand side the numerator in (7) is the loss due to the carbon content in the discharge mass, the second term is the loss due to CO content, the third term is the loss in the flue gas, and the fourth term in the heat loss in the wall of the combustor.

It is observed that the combustion efficiency for both single and double layer porous media fluctuates between $58 \%$ and $73 \%$ in the entire range of fuel-air equivalence ratio. The general trend in the figure suggests that single layer porcelain gives marginally higher combustion efficiency compared to double layer alumina and porcelain. A maximum combustion efficiency of $73 \%$ is recorded at fuel-air equivalence ratio of 0.52 for single layer porcelain. On the other hand, a maximum combustion efficiency of $68 \%$ is attained for double layer porous media at fuel-air equivalence ratio of 0.57 . It has been reported by Charoensuk and Lapirattanakun [22] that it is possible to achieve combustion efficiency in excess of $80 \%$ in a stacked porous combustor. However, the said value is attained when the $\mathrm{CO}$ emission is low and the burner is incorporated with a staged air supply. The surface temperature profile at maximum combustion efficiency for single layer porcelain is shown in Figure 6.

In a burner application, the combustion efficiency is generally governed by the ratio between the theoretical and actual amount of fuel-air mixture [23]. It can also be interpreted as the ratio of the useful heat to the amount of heat input in the burner. For single layer porcelain, when the fuel-air equivalence ratio is gradually enriched, the combustion efficiency deteriorates and diminishes to an 
TABLE 4: Uncertainty of the measured data for the double layer porcelain and alumina in the range of fuel-air equivalence ratio.

\begin{tabular}{|c|c|c|c|c|c|c|}
\hline \multirow{3}{*}{ Fuel-air equivalence ratio } & \multicolumn{6}{|c|}{ Uncertainty } \\
\hline & Surface temperature & $\dot{m}_{f}$ & $V$ & $I$ & $\mathrm{CO}$ & $\mathrm{NO}_{x}$ \\
\hline & $\left({ }^{\circ} \mathrm{C}\right)$ & $\mathrm{L} / \mathrm{min}$ & Volt & Amp & ppm & ppm \\
\hline 0.20 & $0.8 \%$ & $2.1 \%$ & $1.9 \%$ & $0.9 \%$ & $1.7 \%$ & $0.0 \%$ \\
\hline 0.30 & $1.1 \%$ & $2.2 \%$ & $1.8 \%$ & $1.2 \%$ & $1.8 \%$ & $0.0 \%$ \\
\hline 0.35 & $0.9 \%$ & $2.0 \%$ & $1.6 \%$ & $1.1 \%$ & $1.6 \%$ & $0.0 \%$ \\
\hline 0.42 & $1.2 \%$ & $1.7 \%$ & $1.9 \%$ & $1.1 \%$ & $1.5 \%$ & $1.0 \%$ \\
\hline 0.57 & $0.9 \%$ & $1.8 \%$ & $2.0 \%$ & $1.1 \%$ & $1.5 \%$ & $1.0 \%$ \\
\hline 0.59 & $1.0 \%$ & $1.9 \%$ & $2.1 \%$ & $1.3 \%$ & $1.4 \%$ & $0.0 \%$ \\
\hline 0.60 & $1.2 \%$ & $1.7 \%$ & $2.2 \%$ & $1.4 \%$ & $1.7 \%$ & $0.0 \%$ \\
\hline 0.61 & $1.4 \%$ & $1.9 \%$ & $2.1 \%$ & $1.2 \%$ & $1.9 \%$ & $1.0 \%$ \\
\hline
\end{tabular}

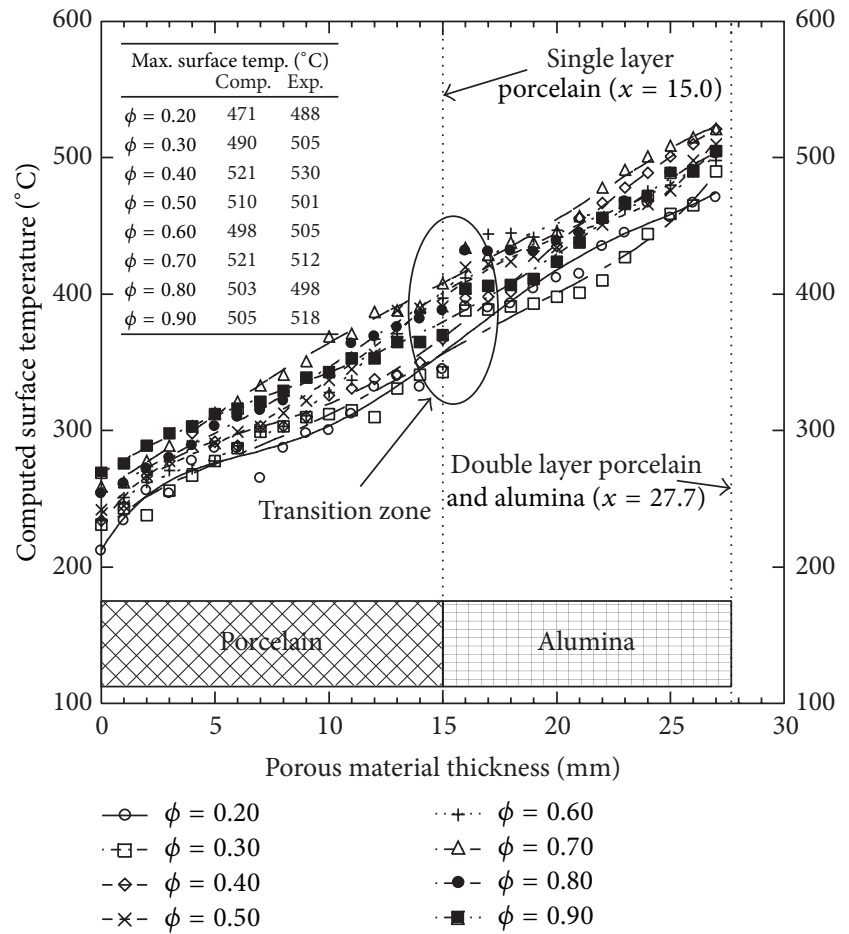

FIGURE 4: Computed surface temperature distributions against porous material thickness at various fuel-air equivalence ratios.

approximately $60 \%$. The reduced combustion efficiency is supported by the temperature profile images captured in the experiment using the thermal imager. The augmentation in the fuel-air equivalence ratio towards the rich region (Figures $7(\mathrm{a}), 7(\mathrm{~b})$, and $7(\mathrm{c})$ ) is accompanied by a reduction in the maximum surface temperature recorded by the imager. Since the wall temperature of the burner only shows minor fluctuations (maximum $5^{\circ} \mathrm{C}$ ), there is little, if any, effect of this temperature on the overall heat transfer. This implies that as the amount of fuel supplied is increased, lack of oxygen prevents complete combustion in the burner and contributed towards the reduced combustion efficiency. Furthermore, since the conduction and convection heat transfer mechanisms are dominant, an improved heat transfer at higher surface temperature for the porous media is evident.

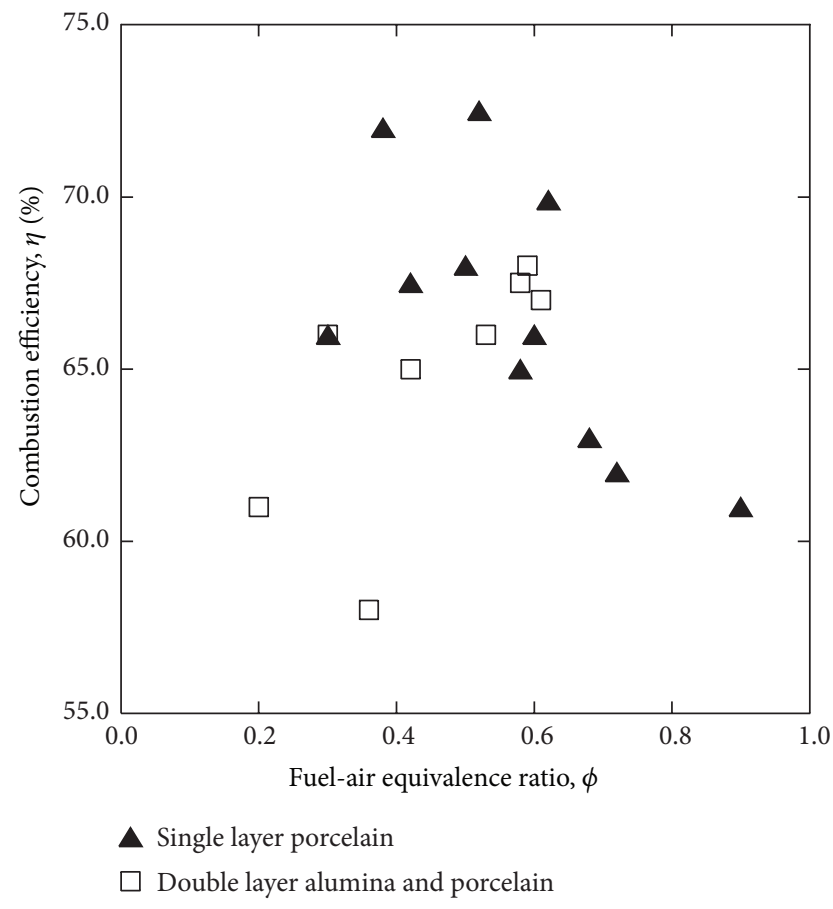

FIGURE 5: Combustion efficiency against fuel-air equivalence ratio.

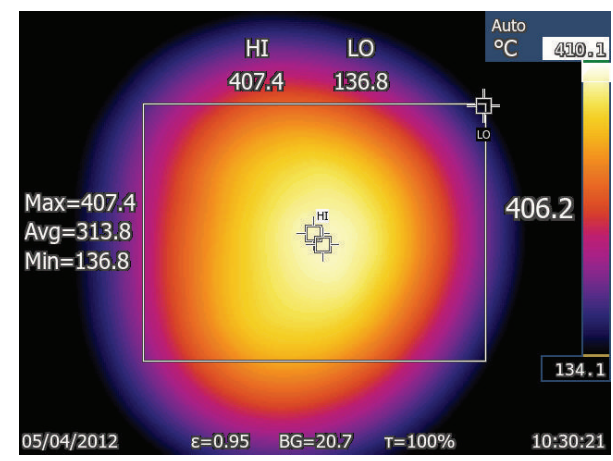

FIGURE 6: Surface temperature profile for single layer porcelain at fuel-air equivalence ratio of 0.52 , maximum combustion efficiency $73 \%$. 


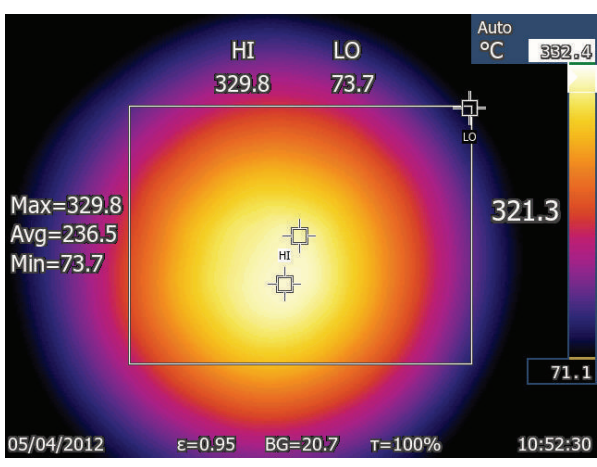

(a)

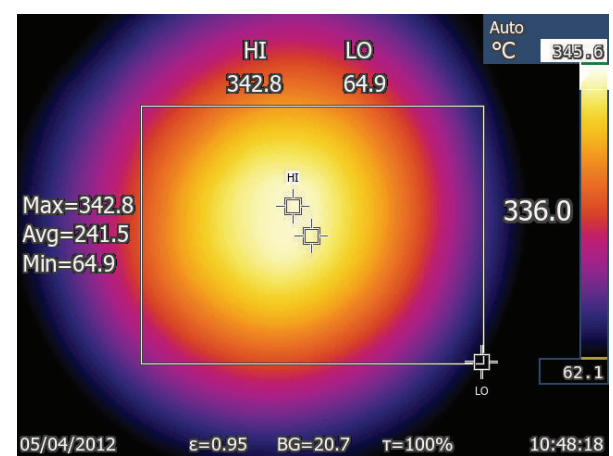

(b)

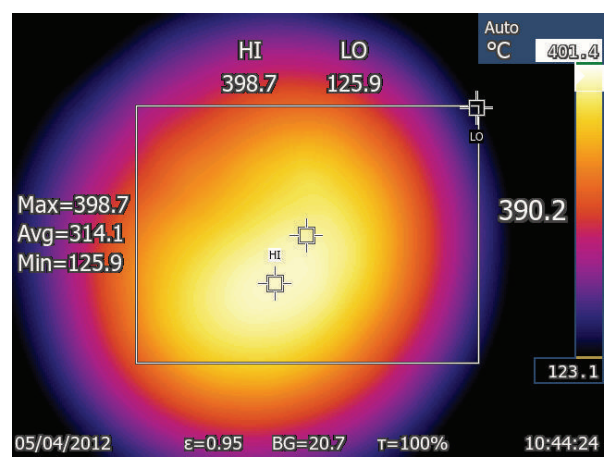

(c)

FIGURE 7: Surface temperature profile for single layer porcelain at various fuel-air equivalence ratios (a) $\phi=0.90$, (b) $\phi=0.75$, and (c) $\phi=$ 0.68 .

For double layer alumina and porcelain porous media, the deleterious effect of a stacked porous media is evident, as the combustion efficiency is markedly lower at lean fuel-air equivalence ratio.

The temperature profile images for double layer porous media in the lean region of fuel-air equivalence ratio are shown in Figures 8(a) and 8(b). The figures are temperature profiles for two reference points of fuel-air equivalence ratio $(\phi=0.30$ and $\phi=0.35)$. These points represent the lean region of fuel-air equivalence ratio for double layer alumina and porcelain porous media. The surface temperature at these points is considerably higher than the surface temperature of the single layer porcelain only. Furthermore, the wall temperature for double layer is slightly higher than the single layer porcelain, but the maximum temperature fluctuations were less than $10^{\circ} \mathrm{C}$. The concomitant reduction in combustion efficiency is remarkably peculiar, because it suggests that the temperature difference is not the only governing factor for heat transfer mechanism at these regions of fuel-air equivalence ratio.

For single layer porcelain, it has been delineated that in the rich region of fuel-air equivalence ratio the conduction and convective heat transfer are pronounced. However, stacking up the porous media with bigger pore size alumina $(8 \mathrm{ppcm})$ appears to substantially increase the surface temperature but adversely affect the combustion efficiency. This can be partly explained by considering the role of pores in the matrix of the porous media. As the flame propagates downstream towards bigger size pore, the magnitudes of the turbulence intensity are higher. As the intensity increases, reaction rates and turbulent flame speed is higher in alumina. This causes the flame temperature to be significantly higher in this section. However, since the combustion efficiency is negatively affected, it is postulated here that the mechanics of flow in the pores of porous media matrix could have contributed towards the diminishing combustion efficiency.

3.3. CO Emission. The emission level of nitrogen oxides $\left(\mathrm{NO}_{x}\right)$ and carbon monoxide $(\mathrm{CO})$ were measured using combustion analyzer CA-CALC 6203. The probe tip of the combustion analyzer was aligned in the horizontal position to be in the center of the burner with $10 \mathrm{~cm}$ vertical distance from the top surface of the porous media. It seemed reasonable to suppose that the vertical distance of $10 \mathrm{~cm}$ from the top surface of the porous media to the probe tip was sufficient to ensure uniformity across the entire section of the measured plane of combustion surface. All emission readings have the uncertainty of $\pm 5 \mathrm{ppm}$. Figure 9 shows the carbon monoxide (CO) emission level (ppm) against fuel-air equivalence ratio, $\phi$.

This will subsequently reduce the reaction rates and turbulent speed in the double layer alumina and porcelain greater than the single layer porcelain only. Figure 9 reveals that $\mathrm{CO}$ emission level for stacked alumina and porcelain is flatter until the fuel-air equivalence ratio of about 0.55 before it steeply increases as the equivalence ratio approaches the rich region. Emissions of $\mathrm{CO}$ are in the range of 400-800 ppm from the lean limit of 0.20 to 0.55 and markedly increase 


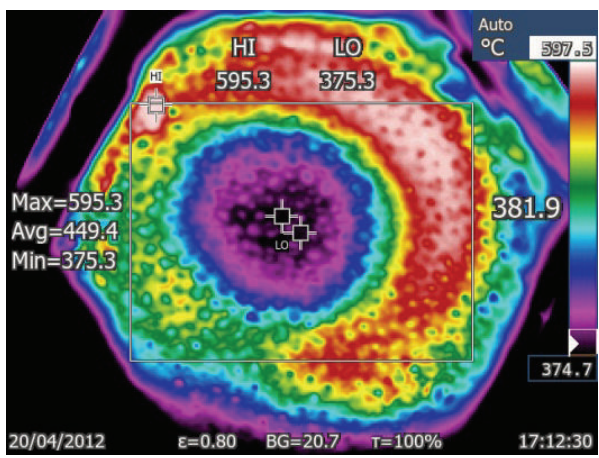

(a)

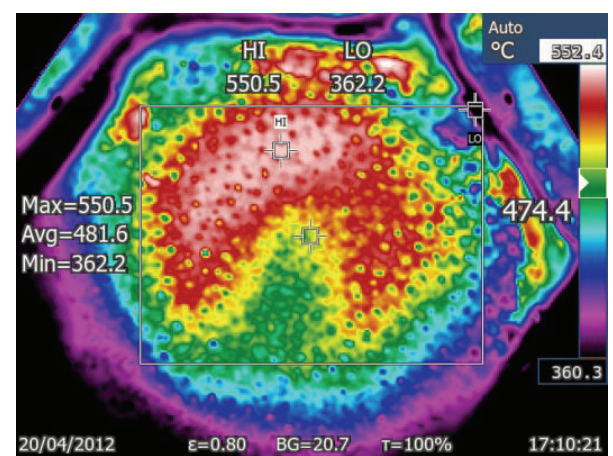

(b)

FIGURE 8: Surface temperature profile for double layer alumina and porcelain at various fuel-air equivalence ratio: (a) $\phi=0.30$ and (b) $\phi=$ 0.35 .

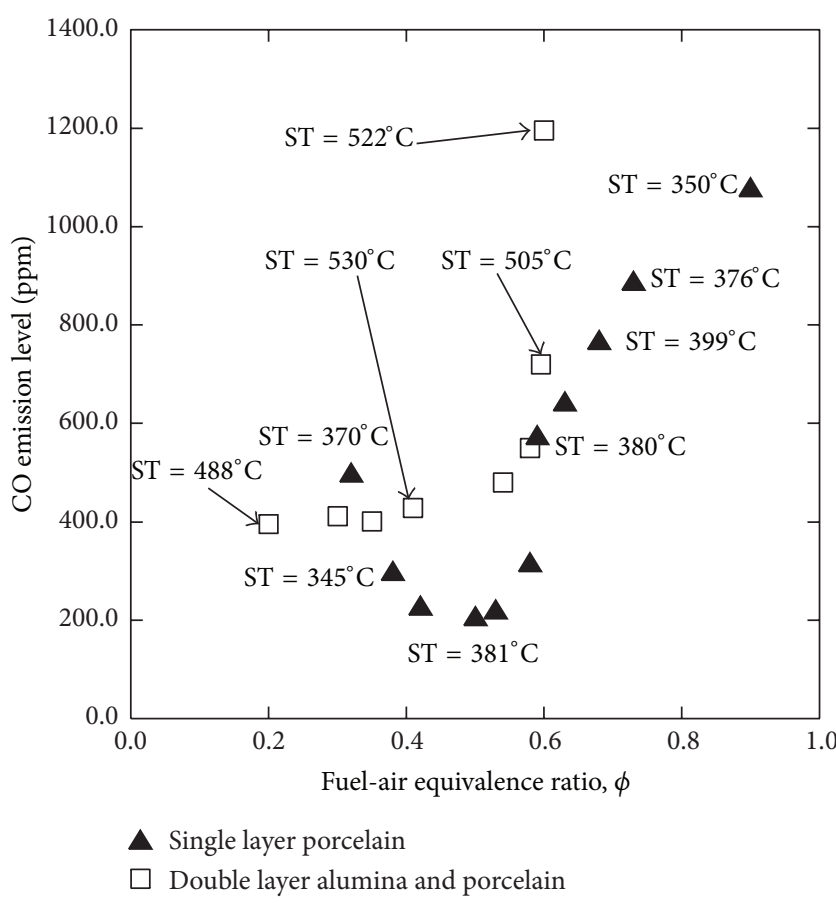

FIGURE 9: CO emission level (ppm) against fuel-air equivalence ratio, $\phi$ for both single (porcelain) and double layer (alumina and porcelain) porous media.

to more than $1200 \mathrm{ppm}$ when the fuel-air equivalence ratio was extended towards rich mixture. It has been elucidated earlier that the incorporation of stacked porous media with different pore size reduces the reaction rates and turbulent speed, but flame stability was moderately enhanced in the lean region of combustion. Furthermore, $\mathrm{CO}$ emission is also a useful indicator of the completeness of combustion. Low level of CO is normally created when the combustion is most complete and negligible amount is generated when the fuel is completely burned. Substantial amount of CO emission recorded in this study suggested a deleterious impact of porous media combustion using butane gas as primary fuel. The fuel premixing chamber designed in our investigation was primarily intended to increase the mixture residence time prior to combustion, by obviating the need of an air compressor which would have been externally driven by an external source. Since the fuel nozzle sits only few millimeters from the opening of the premixed chamber, the air induction was mainly achieved via entrainment to the premixed chamber. However, since the amount of CO level is appreciably high, it can be postulated that the concept of premixing the butane gas with entrained air brought certain degree of shortcomings which has impaired the combustion efficiency. Figure 9 also illustrates that the amount of $\mathrm{CO}$ generated for single layer porcelain is equally high, with the maximum value comparable to the double layer alumina and porcelain. The measured value is fairly moderate at around $500 \mathrm{ppm}$ for lean fuel-air equivalence ratio but gradually reduces as the mixture is enriched. There is a fair degree of scatter lying above the minimum value of about $200 \mathrm{ppm}$ and shows increasing trend when the mixture was continually enriched. The surface temperature is also shown in Figure 8. Those highlighted in the figure represent vital surface temperatures at extreme ends of fuel-air equivalence ratio and other points which have temperature difference of about $\pm 20^{\circ} \mathrm{C}$ with contiguous measuring points. Evidently, when comparison is made for both single and double layer porous media, the surface temperatures do not greatly affect the amount of $\mathrm{CO}$ emission recorded across the range of equivalence ratio in the experiment. However, the difference in the surface temperature of double layer alumina and porcelain is apparent, with maximum temperature difference of about $200^{\circ} \mathrm{C}$. By arranging the smaller pore size porcelain upstream of the flow, the finer porous medium structure $(16 \mathrm{ppcm})$ creates greater flow resistance compared to alumina $(8 \mathrm{ppcm})$. The turbulence intensity is smaller in small pore size, as described by Hall and Hiatt [24]. As soon as the flow enters alumina with bigger pore size, the turbulence intensity increases and the flow propagates downstream towards the top surface of alumina. This in particular dictates that concomitant increase in the turbulence intensity is thought to be wholly beneficial for the significant increment in the measured temperature of the double layer porous media.

3.4. $\mathrm{NO}_{x}$ Emission. Figure 10 represents the $\mathrm{NO}_{x}$ emission level against fuel-air equivalence ratio for both single layer 


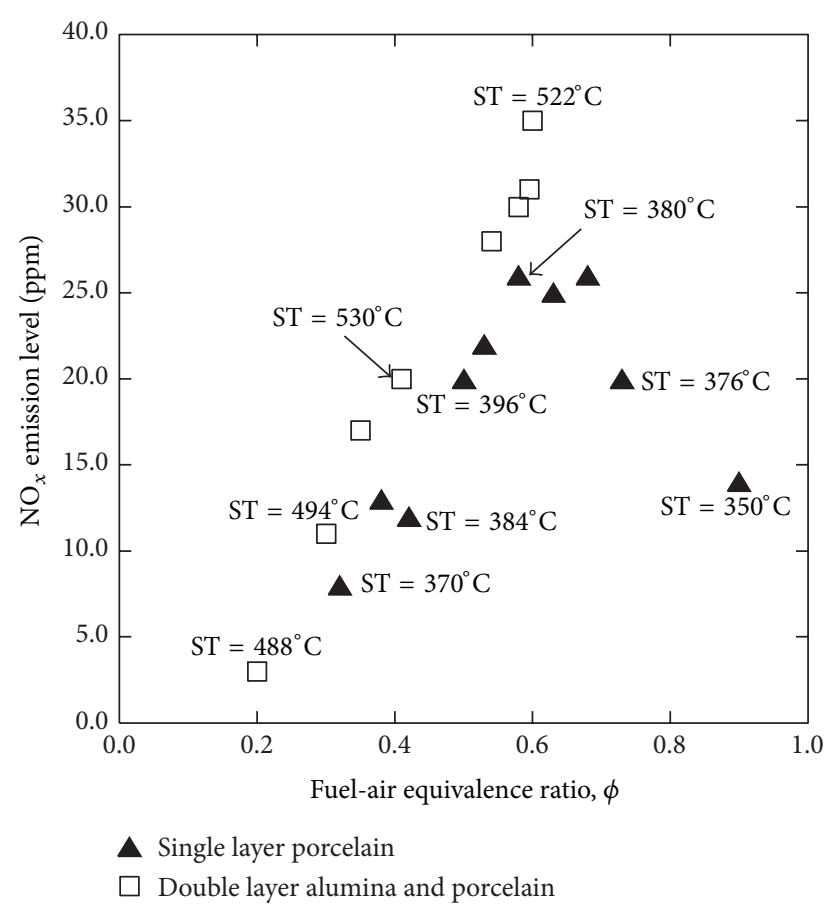

FIGURE 10: $\mathrm{NO}_{x}$ emission level (ppm) against fuel-air equivalence ratio, $\phi$ for both single (porcelain) and double layer (alumina and porcelain) porous media.

porcelain and double layer alumina and porcelain. The surface temperatures at selected points of fuel-air equivalence ratio are also highlighted in the figure for both single and double layer porous media. The data plotted in Figure 10 clearly shows a linear correlation for double layer alumina and porcelain porous media in the ranges of fuel-air equivalence ratio investigated. For single layer porcelain, an increasing trend of the $\mathrm{NO}_{x}$ level is apparent and exhibits maxima at fuel-air equivalence ratio of about 0.60 before the level diminishes towards the rich limit of fuel-air equivalence ratio. Furthermore, essential features in the figure indicate that the level of $\mathrm{NO}_{x}$ emission is clearly higher for double layer porous media compared to single layer porcelain at all operating ranges of fuel-air equivalence ratio. Maximum level of $\mathrm{NO}_{x}$ for single layer and double layer porous media is $27 \mathrm{ppm}$ and $35 \mathrm{ppm}$, respectively. The sensitivity of $\mathrm{NO}_{x}$ formation is susceptible by two factors: the surface temperature and fuel-air equivalence ratio. When the surface temperature of the combustion zone is high, the amount of $\mathrm{NO}_{x}$ emission recorded is generally high, as can be shown by comparing the surface temperature of the single and double layer porous media. This reflects the dependency of the $\mathrm{NO}_{x}$ formation on the surface temperature.

For double layer porous media, as we sweep from the lean to the rich limit of the equivalence ratio, the level of $\mathrm{NO}_{x}$ increases accordingly. This general trend implies that by increasing the fuel flow rate as the fuel-air equivalence ratio is enriched, the amount of input energy is also increased (since the input energy is the product of fuel flow rate and the calorific value of the fuel). It seems acceptable to suppose that by premixing greater amount of fuel with air, once the combustion stabilizes in the upstream section of the porous media, the flame propagates towards larger pore downstream porous media. In the larger pore porous media (alumina), combustion intensity increases and the surface temperature increases accordingly. However, the maximum surface temperature recorded in our study is not at the richest fuel-air equivalence ratio but shifted slightly towards leaner fuel-air equivalence ratio (approximately 0.57). This shows the caution required to draw a direct conclusion based on this observation alone, because the difficulty arises owing to the complexity and lack of proper understanding of the underlying physics of $\mathrm{NO}_{x}$ formation. This needs to be corroborated further by analyzing the exact temperature distribution to understand the detail mechanism of $\mathrm{NO}_{x}$ formation. The single layer porcelain yields lower surface temperature as all data scatters lying below the measured surface temperature of the double layer porous media. The maximum temperature for the single layer porcelain $\left(399^{\circ} \mathrm{C}\right)$ is $89^{\circ} \mathrm{C}$ lower than the lowest surface temperature of the double layer porous media $\left(488^{\circ} \mathrm{C}\right)$. It is also evident from Figure 9 that the single layer porcelain allows fuel-air equivalence ratio to be enriched to about 0.90 before flashback occurs in the combustion zone. Interestingly, the maximum $\mathrm{NO}_{x}$ emission occurs almost at the same fuel-air equivalence ratio of double layer porous media. It then gradually decreases as the fuel-air equivalence ratio was enriched. Since single layer porous media consists of smaller pore size compared to double layer porous media, there is no transition of the combustion intensity throughout the entire section of the porous media. This could in particular dictate that the path taken by the combustion flow gases does not suffer from adverse combustion intensity changes, as would have taken place in the double layer porous media. Temperature distribution is much more uniform and lower, which inferred the significantly lower amount of $\mathrm{NO}_{x}$ obtained in this section of porous media.

\subsection{Temperature Difference versus Fuel-Air Equivalence Ratio.} The plot of temperature difference against fuel-air equivalence ratio is shown in Figure 11. The temperature difference shown in the figure is based on the temperature difference of surface temperature and the wall temperature for each calculated points of fuel-air equivalence ratio. The wall temperature refers to the average fins temperature attached to the thermoelectric modules. Temperature difference is a more meaningful parameter than the exact surface temperature of the porous media since the electricity generated in thermoelectric modules works on Seebeck effect, which is strongly dependent on temperature difference generated from a burner. Figure 11 shows that the temperature difference for double layer porous media is higher than the single layer porous media in the range of fuel-air equivalence ratio investigated. The maximum temperature difference for double layer porous media is $459^{\circ} \mathrm{C}$ (at fuel-air equivalence ratio of 0.57 ) and for single layer porous media is $400^{\circ} \mathrm{C}$ (at fuel-air equivalence ratio of 0.67 ). For double layer porous media, a change in the fuel-air equivalence ratio does not create perceptible change in the measured temperature difference. However, closer inspection in the figure reveals 


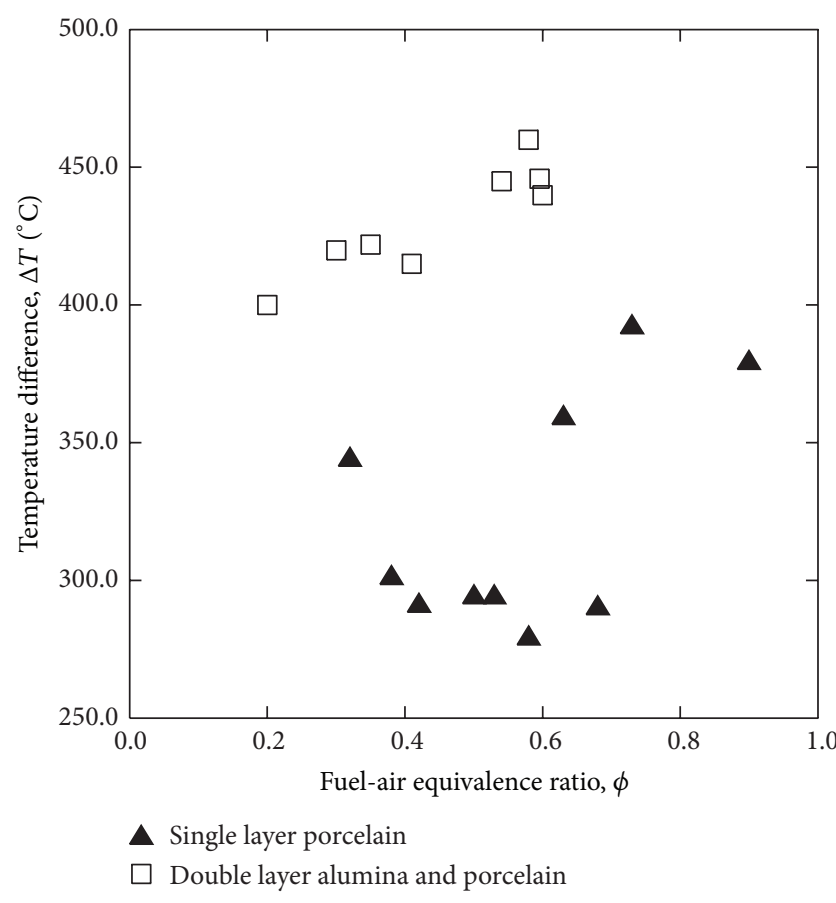

FIGURE 11: Temperature difference $\left({ }^{\circ} \mathrm{C}\right)$ against fuel-air equivalence ratio, $\phi$ for both single (porcelain) and double layer (alumina and porcelain) porous media.

that there are few scatters lying in the temperature difference region of approximately $450^{\circ} \mathrm{C}$ when the fuel-air equivalence ratio is nearing the flashback (rich) region. This is the highest temperature difference for the ranges of fuel-air equivalence ratio varied in this study. It has been expounded earlier that flashback is characterized by the sudden reverse flow towards the upstream section of the stacked porous media at rich spectrum of fuel-air equivalence ratio. However, since the thermal conductivity of alumina $(40 \mathrm{~W} / \mathrm{mK})$ is greater than the thermal conductivity of porcelain (only $1.5 \mathrm{~W} / \mathrm{mK}$ ), a new thermal equilibrium for double layer alumina and porcelain is significantly longer to attain compared to single layer porous media. Heat feedback from the porcelain to the alumina occurs and resulted in higher temperature difference generated in the burner. For single layer porous media using porcelain, low thermal conductivity and smaller pore size have adversely affected the temperature difference obtained, as illustrated by the lower temperature difference when comparison is made with double layer porous media. Combustion intensity is much more rigorous in bigger pore size alumina than in the smaller pore porcelain. On the other hand, the calmer combustion intensity in the smaller pore porcelain has enhanced combustion stability, but at the expense of the lower temperature difference obtained in the section. In addition, when the fuel-air equivalence ratio generally recedes towards the lean mixture, temperature difference is lowest, owing to the compounding effect of reduced combustion intensity and low energy input from the supplied butane gas.

3.6. Electric Power Output from Thermoelectric Modules. The temperatures difference between the porous media surface, voltage $(V)$, and current $(A)$ are generated from the raw data

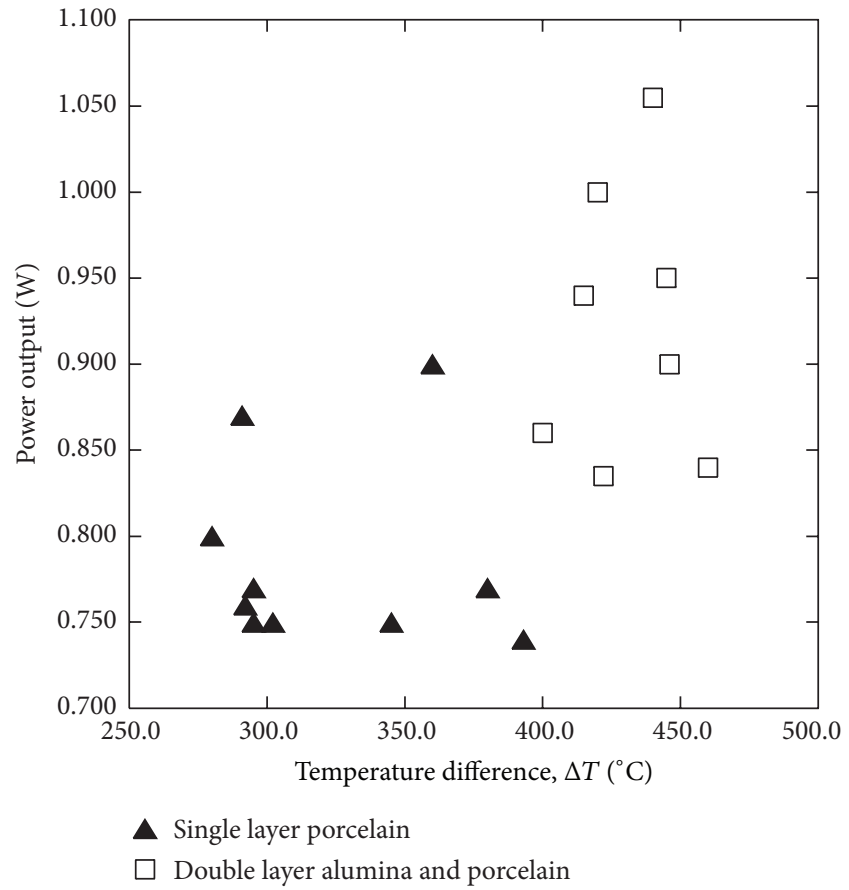

Figure 12: Temperature difference $\left({ }^{\circ} \mathrm{C}\right)$ against power output $(\mathrm{W})$ for both single porcelain and double layer alumina and porcelain porous media.

of this study and they are tabulated in Table 5 below. The data tabulated in Table 5, in particular voltage and current can be extracted to give power output (Watt) and this is plotted against the temperature difference as shown in Figure 12.

The electric power (Watt) generated from this study is found to be marginally higher for double layer alumina and porcelain compared to single layer porcelain. In general, it is observed that an increase in the temperature difference resulted in higher power output produced by the system. The lowest power obtained using the system was found to be about $0.750 \mathrm{~W}$ for single layer porcelain and the highest is about $1.05 \mathrm{~W}$, obtained in the double layer porous media. Six PbSnTe thermoelectric modules used in the system were thermally connected in parallel and electrically connected in series. Each leg of the thermoelectric modules was connected in series and the final pair of legs forms the terminal for voltage and current measurement. The current and voltage output were measured using the digital multimeter. The wall temperature of the burner was measured using Fluke Ti27 $9 \mathrm{~Hz}$ thermal imager, without encountering significant fluctuations in the measured temperature throughout the entire experiment. It was also observed that the wall temperature consistently pulsated between $3^{\circ} \mathrm{C}$ and $5^{\circ} \mathrm{C}$ and they were thought to have very little influence on the outcome of the overall temperature difference attained in this study.

3.7. Feasibility of the Proposed Burner for TE Power Generation. A porous burner for TE power generation could be viewed as an alternative power device. The primary feature of our designed is a strong dependence of the thermal and electrical variables on the fuel-air equivalence ratio. A change 
TABLE 5

\begin{tabular}{|c|c|c|c|c|c|}
\hline \multicolumn{3}{|c|}{ Double layer alumina and porcelain } & \multicolumn{3}{|c|}{ Single layer porcelain } \\
\hline Temperature difference $\left({ }^{\circ} \mathrm{C}\right)$ & Voltage (V) & Current (A) & Temperature difference $\left({ }^{\circ} \mathrm{C}\right)$ & Voltage (V) & Current (A) \\
\hline 401 & 10.64 & 0.081 & 345 & 10.02 & 0.080 \\
\hline 459 & 10.35 & 0.082 & 310 & 9.98 & 0.087 \\
\hline 441 & 10.45 & 0.085 & 295 & 10.11 & 0.076 \\
\hline 441 & 11.30 & 0.085 & 341 & 10.55 & 0.070 \\
\hline 414 & 11.46 & 0.086 & 307 & 10.19 & 0.075 \\
\hline 414 & 10.85 & 0.077 & 306 & 9.45 & 0.08 \\
\hline 410 & 11.10 & 0.084 & 289 & 9.75 & 0.083 \\
\hline \multirow[t]{4}{*}{434} & 12.10 & 0.087 & 361 & 10 & 0.090 \\
\hline & & & 399 & 10.05 & 0.074 \\
\hline & & & 376 & 9.78 & 0.076 \\
\hline & & & & 9.65 & 0.071 \\
\hline
\end{tabular}

in fuel-air equivalence ratio is associated with the change in chemical energy of the fuel. This leads to various thermal and electrical parameters of the burner, which could be optimized for specific TE power generation. The surface temperature of a double layer porous burner is considerably higher than the single layer throughout the entire range of fuelair equivalence ratio. However, the combustion efficiency for a double layer is marginally lower than the single layer. This indicates that operating the single layer burner in the lean region is beneficial compared to the double layer. Furthermore, the system is temperature dependent, and the maximum permissible operating temperature of the TE cells must be strictly adhered. It is also shown that the $\mathrm{CO}$ and $\mathrm{NO}_{x}$ is generally low in the lean region of combustion. For $\mathrm{CO}$, this reduction is due to completeness of combustion, and, for $\mathrm{NO}_{x}$, the observed trend is fundamentally related to the temperature profiles. The emission findings accord well with the surface temperatures of the burner in the lean operating region. It is also interesting to note that the double layer porous burner yields greater power output throughout the range of fuel-air equivalence ratio. However, the calculated power is very low, leading to a reduced overall efficiency of the system. Therefore, if the system improvement were needed in the current setup, the use of high performance semiconductor materials must be chosen for future TE power generation. It is also important to note that butane is used in our current study. If portability of the fuel used is of the utmost priority, our present setup with butane gas has been demonstrated to be feasible. However, other commercially available fuels, such as propane or methane can be employed without major hardware modifications.

\section{Conclusion}

An experimental study has been conducted to evaluate the characteristics of a porous burner for thermoelectric (TE) power generation. Two types of configurations were assessed: double layer porous burner composed of alumina and porcelain and single layer porcelain only. The characteristics of the burner are presented in terms of the combustion efficiency, surface temperature, and the emission level. The electricity was generated using six PbSnTe thermoelectric
(TE) modules, which were attached to the wall of the burner. The surface temperature for the double layer porous media is significantly higher than the single layer. The flow transition from the smaller pore size porcelain $(16 \mathrm{ppcm})$ to the higher pore size alumina $(8 \mathrm{ppcm})$ has contributed to the higher surface temperature recorded for the double layer porous media. In the range of fuel-air equivalence ratio investigated, for double layer porous media, $\mathrm{NO}_{x}$ emission increases linearly and peaked at fuel-air equivalence ratio of 0.60. Similar trend is also observed for single layer porcelain, but level decreased when the fuel-air equivalence ratio was extended further towards the rich region. The amount of $\mathrm{CO}$ emission is generally high owing to the complex flow mechanism as the flame propagates downstream from the smaller pore size porcelain to bigger pore size alumina. The electric power generated is calculated based on the current and voltage produced from the TE modules. The values are generally dependent on the temperature difference between the burner and the wall, with higher power generated at greater temperature difference.

\section{Conflict of Interests}

The authors declare that there is no conflict of interests regarding the publication of this paper.

\section{Acknowledgment}

This work was supported by Ministry of Higher Education, Malaysia, under the Fundamental Research Grant Scheme (FRGS) (Grant no. 6071236).

\section{References}

[1] K. Qiu and A. C. S. Hayden, "Integrated thermoelectric generator and application to self-powered heating systems," in Proceedings of the 25th International Conference on Thermoelectrics (ICT '06), pp. 198-203, Vienna, Austria, August 2006.

[2] K. Qiu and A. C. S. Hayden, "A natural-gas-fired thermoelectric power generation system," Journal of Electronic Materials, vol. 38, no. 7, pp. 1315-1319, 2009. 
[3] D. Champier, J. P. Bedecarrats, M. Rivaletto, and F. Strub, "Thermoelectric power generation from biomass cook stoves," Energy, vol. 35, no. 2, pp. 935-942, 2010.

[4] J. Yang and F. R. Stabler, "Automotive applications of thermoelectric materials," Journal of Electronic Materials, vol. 38, no. 7, pp. 1245-1251, 2009.

[5] S.-K. Kim, B.-C. Won, S.-H. Rhi, S.-H. Kim, J.-H. Yoo, and J.C. Jang, "Thermoelectric power generation system for future hybrid vehicles using hot exhaust gas," Journal of Electronic Materials, vol. 40, no. 5, pp. 778-783, 2011.

[6] Y. D. Deng, W. Fan, K. Ling, and C. Q. Su, "A 42-V electrical and hybrid driving system based on a vehicular waste-heat thermoelectric generator," Journal of Electronic Materials, vol. 41, no. 6, pp. 1698-1705, 2012.

[7] J. Posthill, A. Reddy, E. Siivola et al., "Portable power sources using combustion of butane and thermoelectrics," in Proceedings of the 24th International Conference on Thermoelectrics (ICT '05), pp. 520-523, Clemson, SC, USA, June 2005.

[8] M. M. Rahman and R. Shuttleworth, "Thermoelectric power generation for battery charging," in Proceedings of the International Conference on Energy Management and Power Delivery (EMPD '95), pp. 186-191, November 1995.

[9] K. Yoshida, S. Tanaka, S. Tomonari, D. Satoh, and M. Esashi, "High-energy density miniature thermoelectric generator using catalytic combustion," Journal of Microelectromechanical Systems, vol. 15, no. 1, pp. 195-203, 2006.

[10] J. R. Howell, M. J. Hall, and J. L. Ellzey, "Combustion of hydrocarbon fuels within porous inert media," Progress in Energy and Combustion Science, vol. 22, no. 2, pp. 121-145, 1996.

[11] C. Periasamy, S. K. Sankara-Chinthamony, and S. R. Gollahalli, "Experimental evaluation of evaporation enhancement with porous media in liquid-fueled burners," Journal of Porous Media, vol. 10, no. 2, pp. 137-150, 2007.

[12] S. Vijaykant and A. K. Agrawal, "Liquid fuel combustion within silicon-carbide coated carbon foam," Experimental Thermal and Fluid Science, vol. 32, no. 1, pp. 117-125, 2007.

[13] C. Periasamy and S. R. Gollahalli, "Experimental investigation of kerosene spray flames in inert porous media near lean extinction," Energy and Fuels, vol. 25, no. 8, pp. 3428-3436, 2011.

[14] S. Jugjai and N. Polmart, "Enhancement of evaporation and combustion of liquid fuels through porous media," Experimental Thermal and Fluid Science, vol. 27, no. 8, pp. 901-909, 2003.

[15] T. L. Marbach and A. K. Agrawal, "Experimental study of surface and interior combustion using composite porous inert media," Journal of Engineering for Gas Turbines and Power, vol. 127, no. 2, pp. 307-313, 2005.

[16] M. T. Smucker and J. L. Ellzey, "Computational and experimental study of a two-section porous burner," Combustion Science and Technology, vol. 176, no. 8, pp. 1171-1189, 2004.

[17] K. Hanamura, T. Kumano, and Y. Iida, "Electric power generation by super-adiabatic combustion in thermoelectric porous element," Energy, vol. 30, no. 2-4, pp. 347-357, 2005.

[18] W.-H. Chen, C.-Y. Liao, C.-I. Hung, and W.-L. Huang, "Experimental study on thermoelectric modules for power generation at various operating conditions," Energy, vol. 45, no. 1, pp. 874$881,2012$.

[19] K. Mustafa, S. Abdullah, M. Abdullah, K. Sopian, and A. Ismail, "Experimental investigation of the performance of a liquid fuelfired porous burner operating on kerosene-vegetable cooking oil (VCO) blends for micro-cogeneration of thermoelectric power," Renewable Energy, vol. 74, pp. 505-516, 2015.
[20] P.-F. Hsu, W. D. Evans, and J. R. Howell, "Experimental and numerical study of premixed combustion within nonhomogeneous porous ceramics," Combustion Science and Technology, vol. 90, no. 1-4, pp. 149-172, 1993.

[21] A. Gungor, "Analysis of combustion efficiency in CFB coal combustors," Fuel, vol. 87, no. 7, pp. 1083-1095, 2008.

[22] J. Charoensuk and A. Lapirattanakun, "On flame stability, temperature distribution and burnout of air-staged porous media combustor firing LPG with different porosity and excess air," Applied Thermal Engineering, vol. 31, no. 16, pp. 3125-3141, 2011.

[23] T. D. Eastop and A. McConkey, Applied Thermodynamics for Engineering Technologies, Prentice Hall, London, UK, 1993.

[24] M. J. Hall and J. P. Hiatt, "Exit flows from highly porous media," Physics of Fluids, vol. 6, no. 2, pp. 469-479, 1994. 

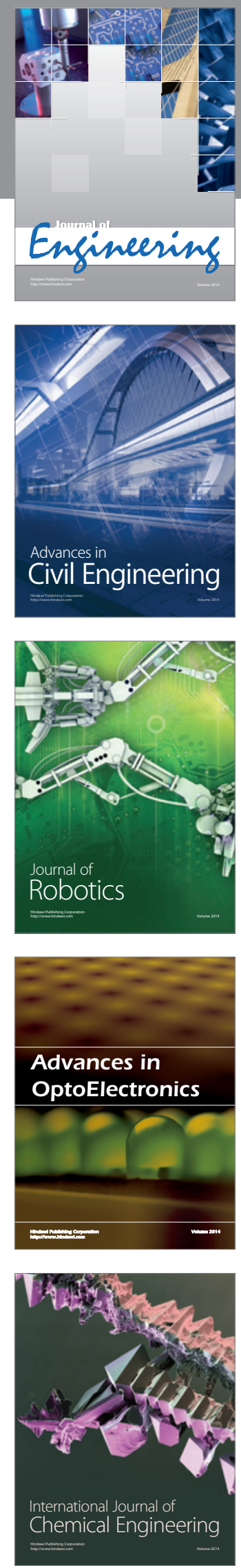

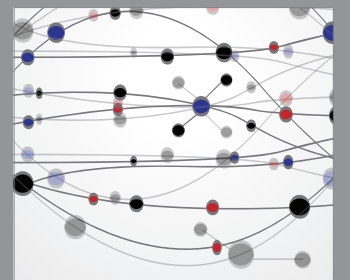

The Scientific World Journal
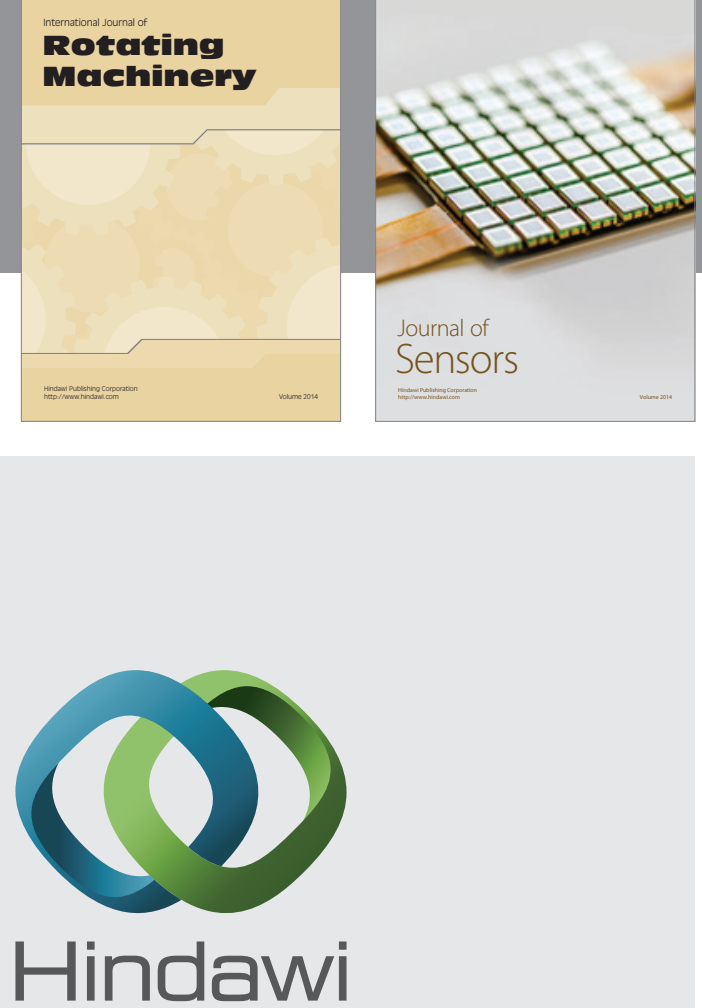

Submit your manuscripts at http://www.hindawi.com
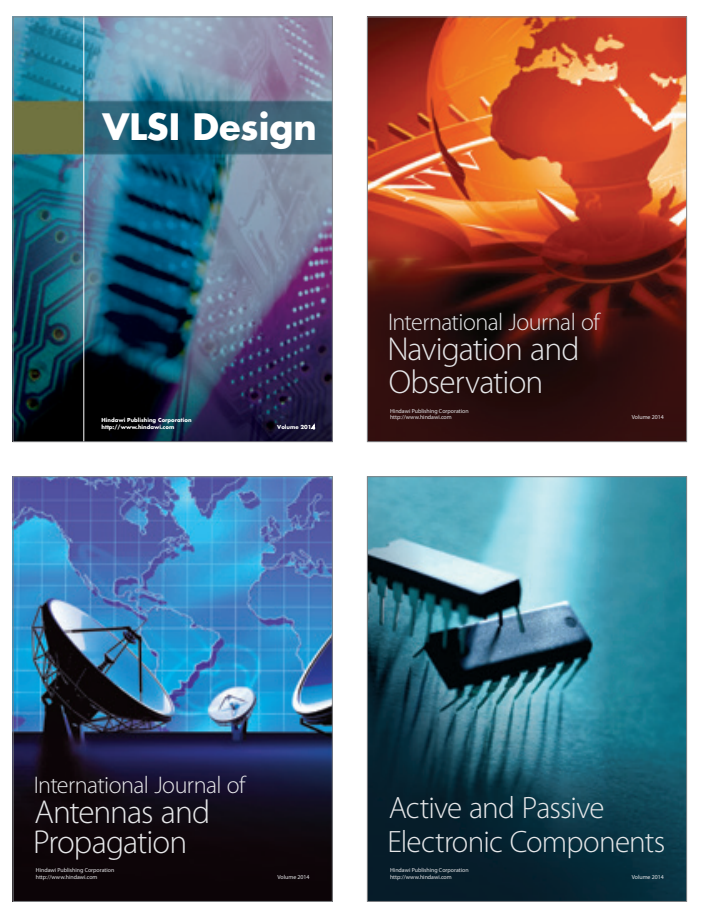
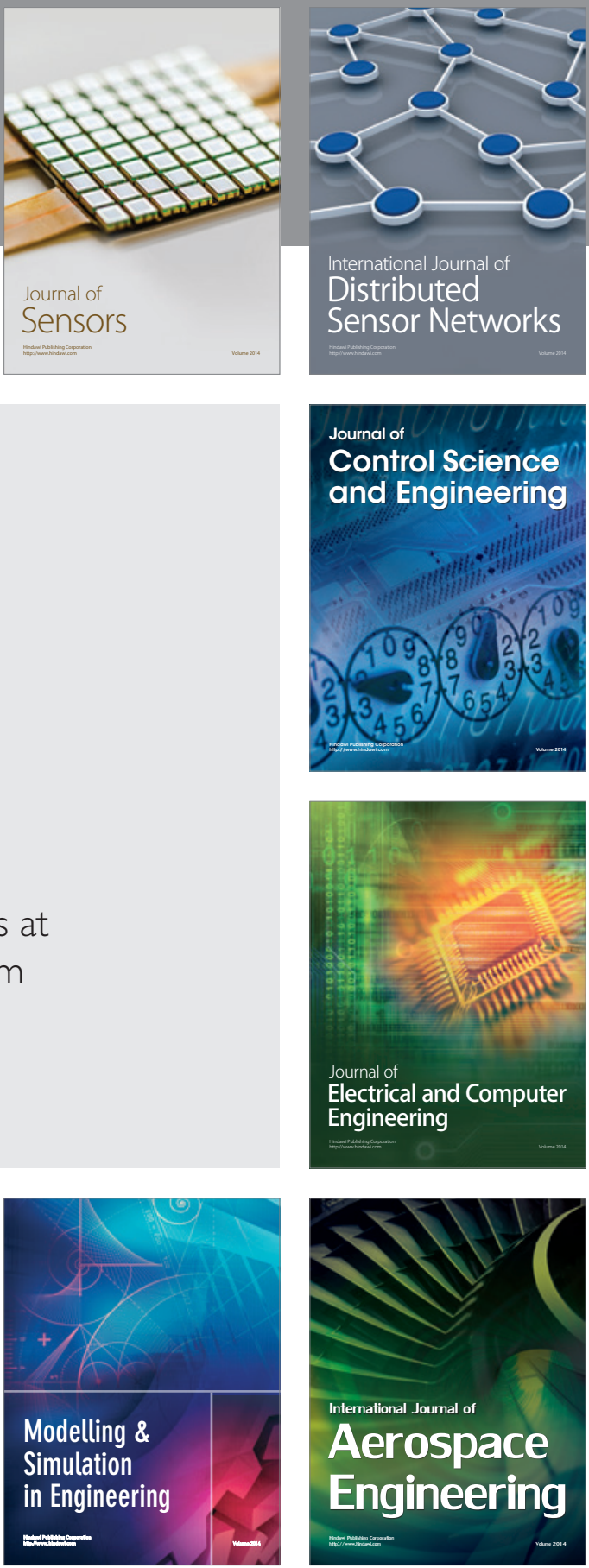

Journal of

Control Science

and Engineering
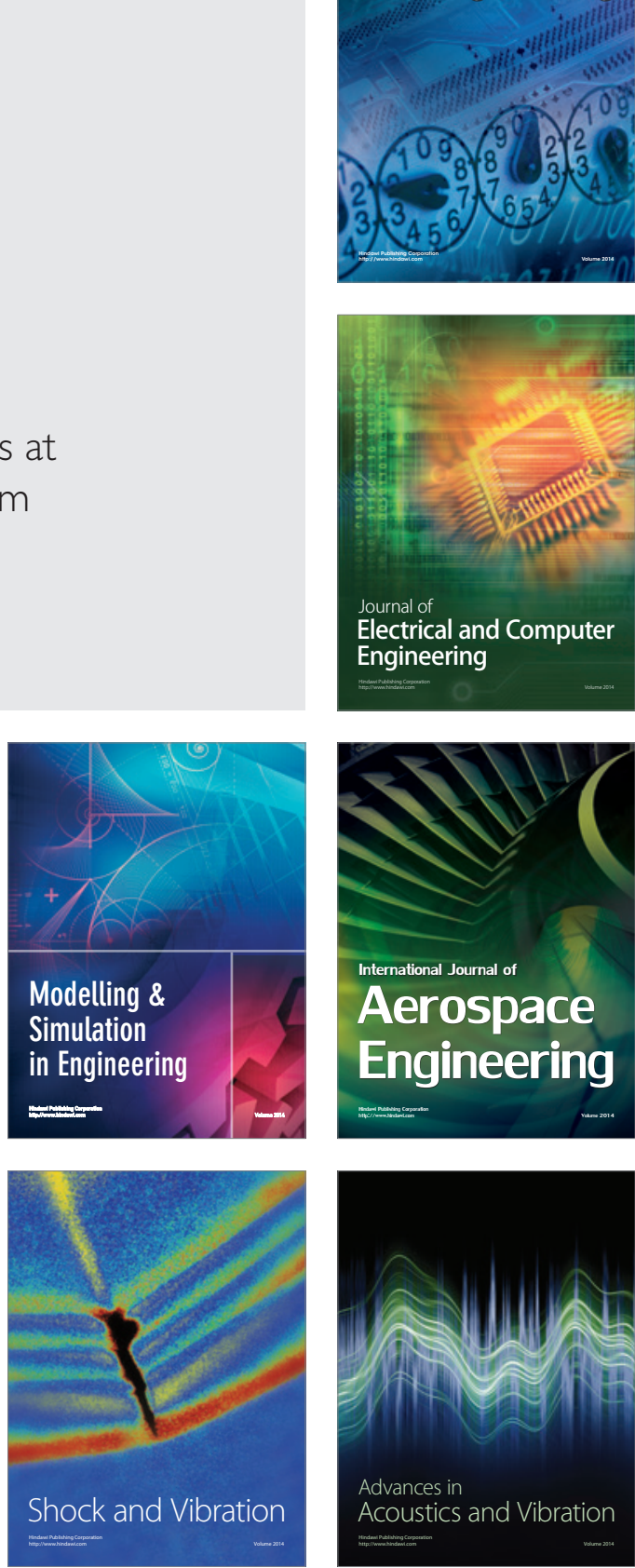